\title{
Correction to: Common Pediatric Medical Emergencies in Office Practice
}

\author{
Bharat Mehra $^{1} \cdot$ Suresh Gupta ${ }^{1}$
}

Published online: 2 October 2017

(C) Dr. K C Chaudhuri Foundation 2017

\section{Correction to: Indian J Pediatr}

https://doi.org/10.1007/s12098-017-2370-9

The published online version contains an inadvertent error. On page 8, under the heading "Approach to a Child with Trauma" there is a box with "Primary Survey \& Resuscitation". The second point needs a small correction. It should read as "Follow A-B-C sequence for evaluation and resuscitation".

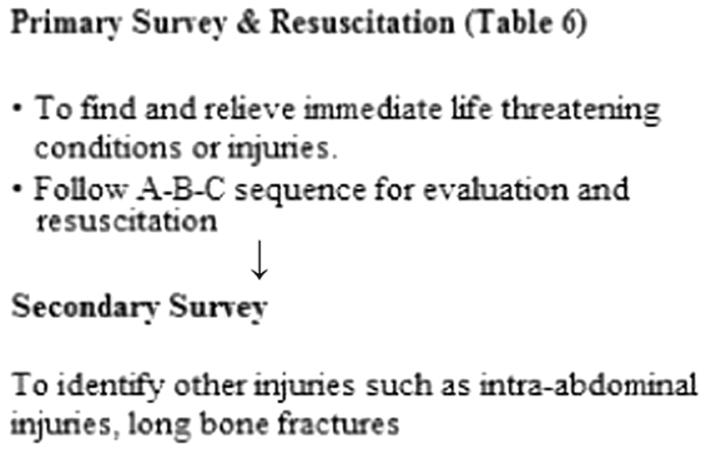

The online version of the original article can be found at https://oi.org/ 10.1007/s12098-017-2370-9

Bharat Mehra

bharatmehra909@gmail.com

1 Division of Pediatric Emergency and Critical Care, Department of Pediatrics, Institute of Child Health, Sir Ganga Ram Hospital,

Rajinder Nagar, New Delhi 110060, India 